\title{
We're all in the same boat: humanising teaching and learning experiences as a way to achieve engaging and interactive online provision
}

\author{
Julia Kotula \\ Arts University Bournemouth \\ Kizzy Beaumont \\ Arts University Bournemouth
}

Keywords: Covid-19; online teaching; student engagement; teacher inhibitions; confidence building; teacher self-perceptions.

\section{The challenge}

Before the pandemic, academic skills sessions at Arts University Bournemouth (AUB) - a specialist arts university - were designed to support creative, visual, and kinesthetic learners. As seasoned learning developers, we were aware that teaching and learning activities need to be inclusive, to respect all students' learning differences, but also relevant, to ensure students engage with them to 'construct meaning' (Biggs, 2003; Souleles, 2013). Idea sharing, encouraging spontaneous remarks, and kinesthetic activities were the foundation of academic skills sessions pre-pandemic. Hence, workshops were interactive, implementing negotiated content via initial needs analysis (Nunan, 1988), scaffolded activities, and discussion of students' comprehension of assignments (Hogan, Nastasi and Pressley, 1999).

With the sudden transition to online provision, our expertise in face-to-face teaching was challenged. Our usual approach with which we felt comfortable, i.e. A3 paper, markers, group discussions, and peer review, suddenly felt impossible to replicate. It became challenging to translate the face-to-face mode of interactivity into a virtual setting and some sessions turned into didactic lectures. The barrier in the form of the screen was tangible, especially in open workshops where the converging of students from various programmes could have led to them wanting to be anonymous and mute. This was 
possibly due to overall anxiety (Simamora, 2020), for example about completing assignments online (Aristovnik et al., 2020), but also because of the lack of confidence in remote online study (Martin, Stamper and Flowers, 2020). Additionally, inhibitions when participating in online discussion, both for students and us, seemed to be a significant barrier (Zhan and Mei, 2013; Muthuprased et al., 2021). The physical interactivity of our workshops had disappeared, which shook our confidence as our professional training and practice relied on this modus operandi. Discursive, engaging study skills workshops now seemed unlikely, but we felt this was something which students and staff needed to attempt to maintain normality and a familiar space to feel comfortable in.

This ambition and desire to maintain normality and familiarity within our sessions to support students' academic development meant that we felt we needed to appear competent in online teaching. We did not want to show our own doubts and inhibitions and so put-up a façade of expertise rather than humanising our practice and acknowledging we were all in the same boat. Our initial thought was that if we maintained our professional demeanours, it would reassure the students that they could continue their studies in a familiar manner. However, what we did not realise was that our own false perception of our role as 'experts', and our expectation that we should be consummate professionals in online teaching, made it a challenging task. This was due to not being able to acknowledge our own struggles with online working, which prevented us from creating open dialogue with the students. As a result, this led to didactic, perceived-as-expert provision rather than transparent and engaging sessions.

\section{The response}

We have become aware that the idea of an 'expert' teacher is not necessarily a useful concept in enhancing students' learning (Lachner, Jarodzka and Nückles, 2016). However, this was a hard notion to move away from when our day-to-day lives were thrown offbalance due to the pandemic. Our instinct, as learning developers, was to try to show students this did not need to impact on their learning and experience. We admit now that our initial thoughts around 'professionalism' and being the 'expert' did not align with the well-researched concept of 'teaching presence,' whereby direct instruction and facilitating discourse are conducive to active and successful learning (Anderson et al., 2001; Stone 
and Springer, 2019). Certainly, focusing on being a 'present teacher' has been more effective than worrying about potentially unprofessional situations, such as a cat or child coming into shot or seamlessly moving between screens or slides. Gradually, continuous reflection on practice and student needs and reframing our own perceptions of our roles helped us to promote interaction and student engagement.

Allowing ourselves to drop our consummate professional demeanours, by showing our human side working within our homes and our inexperience in teaching online, helped us to strike a balance between seriousness and approachability. Using the 'go to' teaching enhancement methods such as peer observations (Race, 2009), weekly team reflective sessions, and student feedback (Hazari and Schnorr, 1999; Mandouit, 2018), we assessed what worked and what did not. Feedback for online sessions showed that the key to supporting engagement and building confidence was the student ability to complete activities within the sessions. This led us to understand that this would require dedicating more time for which we needed to become at ease with silence and our inability to monitor the completion of tasks. We allowed for more flexibility with built-in options for students to choose the most relevant task from a series of scaffolded activities and to work independently. There was a marked difference in feedback between term one and two, with the beginning of term two being the commencement of our new approach. In term one, $70 \%$ of surveyed students gave a comment regarding suggestions for improvement; in term two, this dropped to $28 \%$.

\section{Recommendations}

Growing in confidence enabled us to experiment with additional strategies to increase interactivity, allowing more time for tasks which required it. Some of our most successful steps forward were the simplest: starting each session with a relatable question which would help students to find common ground, e.g., 'what stops you from writing?', or experimenting with shorter (five-ten minutes) and longer (30-45 minutes) tasks, completed individually and within groups. Such activities include:

- Mind mapping of initial thoughts on an assignment before undertaking paired discussion and encouraging the sharing of mind maps within the chat function. 
- Undertaking free writing activities around assignment topics or sharing a Tweet of an essay's main argument.

- Using the poll functions to generate confidence levels in key areas of academic practice, opening the discussion once students can see the results.

- Analysing a paragraph or essay structure in breakout rooms in terms of criticality, academic sources, and coherence before allowing for a whole group discussion in the main room.

In our pursuit of creating meaningful student learning experiences, we learned an important lesson: humanising the experience by acknowledging and admitting that the transition to online learning and teaching was challenging to everyone involved helped us change our perceptions of our roles as learning developers. Accepting the silent moments in the sessions and lowering the expectations that we should be the perfect presenters resulted in increased confidence and evolved practice, and, in turn more engaging, relaxing, and interactive sessions.

\section{References}

Anderson, T., Rourke, L., Garrison, D. R. and Archer, W. (2001) 'Assessing teaching presence in a computer conferencing context', Journal of Asynchronous Learning Networks, 5(2), pp.1-17.

Aristovnik, A., Keržič, D., Ravšelj, D., Tomaževič, N. and Umek, L. (2020) 'Impacts of the COVID-19 pandemic on life of higher education students: a global perspective', Sustainability, 12(20), p.8438. https://doi.org/10.3390/su12208438.

Biggs, J., (2003) 'Aligning teaching for constructing learning', In Higher Education Academy. Available at: https://www.researchgate.net/profile/John-Biggs3/publication/255583992 Aligning Teaching for Constructing Learning/links/5406f fe70cf2bba34c1e8153/Aligning-Teaching-for-Constructing-Learning.pdf (Accessed: 8 June 2021). 
Hazari, S. and Schnorr, D. (1999) 'Leveraging student feedback to improve teaching in web-based courses', The Journal, 26(11), pp.30-38.

Hogan, K., Nastasi, B. K. and Pressley, M. (1999) 'Discourse patterns and collaborative scientific reasoning in peer and teacher-guided discussions', Cognition and Instruction, 17, pp.379-432. https://doi.org/10.1207/S1532690XCI1704 2.

Lachner, A., Jarodzka, H. and Nückles, M. (2016) 'What makes an expert teacher? Investigating teachers' professional vision and discourse abilities', Instructional Science, 44(3), pp.197-203. https://doi.org/10.1007/s11251-016-9376-y.

Mandouit, L. (2018) 'Using student feedback to improve teaching,' Educational Action Research', 26(5), pp.755-769. https://doi.org/10.1080/09650792.2018.1426470.

Martin, F., Stamper, B. and Flowers, C. (2020) 'Examining student perception of readiness for online learning: importance and confidence', Online Learning, 24(2), pp.38-58. https://doi.org/10.24059/olj.v24i2.2053.

Muthuprasad, T., Aiswarya, S., Aditya, K. S. and Jha, G. K. (2021) 'Students' perception and preference for online education in India during COVID-19 pandemic', Social Sciences \& Humanities Open, 3(1), p.100101. https://doi.org/10.1016/i.ssaho.2020.100101.

Nunan, D., (1988) 'Principles for designing language teaching materials' Guidelines: A periodical for classroom language teachers, 10(2), pp.1-24.

Race, P. and Leeds Beckett Teacher Fellows (2009) Using peer observation to enhance teaching. Leeds: Leeds Met Press.

Simamora, R. M., (2020). 'The challenges of online learning during the COVID-19 pandemic: an essay analysis of performing arts education students', Studies in Learning and Teaching, 1(2), pp. 86-103. https://doi.org/10.46627/silet.v1i2.38. 
Souleles, N., (2013) 'The evolution of art and design pedagogies in England: Influences of the past, challenges for the future', International Journal of Art \& Design Education, 32(2), pp. 243-25. https://doi.org/10.1111/j.1476-8070.2013.01753.x.

Stone, C. and Springer, M. (2019) 'Interactivity, connectedness and "teacher-presence": engaging and retaining students online', Australian Journal of Adult Learning, 59(2), pp.146-169.

Zhan, Z. and Mei, H., (2013) 'Academic self-concept and social presence in face-to-face and online learning: perceptions and effects on students' learning achievement and satisfaction across environments', Computers \& Education, 69, pp.131-138. https://doi.org/10.1016/j.compedu.2013.07.002.

\section{Author details}

Julia Kotula has been an EAP practitioner for many years and has recently extended her practice to providing learning development support to students of creative subjects. Her expertise includes teaching Academic Literacies inclusively to students across all levels at university, teaching EAP, and providing support to students with dyslexia and co-occurring difficulties. Her long-existing interests are multilingualism, developing academic writing and critical thinking skills, and the emotional side of studying. More recently she has also become interested in Specific Learning Difficulties and their impact of learning.

Kizzy Beaumont works in learning development, supporting students in developing their academic practice. She gained her PGCE in 2014 and has recently been awarded Senior Fellowship of the Higher Education Academy. As a Study Skills Tutor at AUB, she provides one-to-one academic support, co-delivers open academic practice workshops, and develops and delivers course-specific sessions across a range of programmes. Throughout her academic career, one of her main focuses has been developing programmes, sessions and resources to support and encourage student's engagement with their curriculum. 